\title{
A FORMAÇÃO DOCENTE NO ESTÁGIO SUPERVISIONADO: NARRATIVAS DE EGRESSOS DO CURSO DE PEDAGOGIA
}

\author{
Teaching training in supervised internship: narratives from education from the \\ Pedagogy course
}

\section{Formación docente en la práctica supervisada: narrativas para egresos del curso de Pedagogía}

\author{
Joelson de Sousa Morais* \\ Inês Ferreira de Souza Bragança ${ }^{* *}$
}

\begin{abstract}
Resumo
Neste artigo, de abordagem qualitativa, tomamos como objetivo compreender como professoras/es recém-formadas/os perceberam a docência a partir da experiência do estágio supervisionado no Ensino Fundamental. Para a produção das narrativas pelas/os participantes da pesquisa, pedagogas/os recém-formadas/os de uma instituição de ensino superior privada, no interior do Maranhão, trabalhamos com conversas e questionário como dispositivos metodológicos. O problema de pesquisa questiona: como as/os professoras/es recémformadas/os percebem a docência, a partir da realização do Estágio Supervisionado no Ensino Fundamental pelo qual vivenciaram? Os resultados mostraram que o estágio é uma experiência marcante na formação inicial de professoras/es; apesar de relevante, não fornece todas as bases para se atuar profissionalmente, mas possibilita contribuições fundamentais para os futuros docentes.
\end{abstract}

PALAVRAS-CHAVE: Estágio supervisionado. Formação de professores. Narrativas.

\begin{abstract}
In this article, with a qualitative approach, we aim to understand how recent teachers / teachers perceived teaching from the experience of supervised internship in elementary school. For the production of the narratives by the research participants, educators / recent graduates of a private higher education institution, in the interior of Maranhão, we work with conversations
\end{abstract}

\footnotetext{
* Doutorando em Educação (Bolsista CAPES) pela Universidade Estadual de Campinas (UNICAMP). Mestre em Educação pela Universidade Federal do Rio Grande do Norte (UFRN). Pesquisador do Grupo de Estudos e Pesquisas em Educação Continuada (GEPEC/UNICAMP), do Grupo Interinstitucional de Pesquisaformação Polifonia (UNICAMP/UERJ), do Grupo de Pesquisas Interdisciplinares: Educação, Saúde e Sociedade (UEMA/CNPq) e do Núcleo de Pesquisa em Educação, Formação Docente, Ensino e Práticas Educativas (NUPEFORDEPE/UFPI). E-mail: joelsonmorais@hotmail.com. Orcid: Orcid: https://orcid.org/0000- 0003- 1893- 1316.

** Pós-Doutorado pelo programa de Pós-Graduação em Educação da Pontifícia Universidade Católica do Rio Grande do Sul (PUC/RS).e Doutora em Ciências da Educação pela Universidade de Évora-Portugal. Professora Doutora da Faculdade de Educação da Universidade Estadual de Campinas (FE/UNICAMP) e professora colaboradora do Programa de Pós-Graduação Processos Formativos e Desigualdades Sociais da Faculdade de Formação de Professores da Universidade Estadual do Rio de Janeiro (FFP/UERJ). Pesquisadora do Grupo de Estudos e Pesquisas em Educação Continuada (GEPEC/UNICAMP), do Núcleo de Pesquisa e Extensão Vozes da Educação (FFP/UERJ) e coordenadora do Grupo Interinstitucional de Pesquisaformação Polifonia (UNICAMP/UERJ). E-mail: inesbraganca@uol.com.br. Orcid: https://orcid.org/0000- 0003- 4782- 1167.
} 
and questionnaires as methodological devices. The research problem asks: how did the recently graduated teachers perceive teaching, from the supervised internship in elementary school for which they experienced? The results showed that the internship is a remarkable experience in the initial training of teachers; although relevant, it does not provide all the bases for acting professionally, but it makes fundamental contributions for future teachers.

KEYWORDS: Supervised internship. Teacher training. Narratives.

\section{Resumen}

En este artículo, con un enfoque cualitativo, pretendemos comprender cómo los docentes / docentes recientes perciben la docencia a partir de la experiencia del internado supervisado en la escuela primaria. Para la producción de las narrativas por parte de los participantes de la investigación, educadores / recién graduados de una institución privada de educación superior, en el interior de Maranhão, se trabaja con conversaciones y cuestionarios como dispositivos metodológicos. El problema de investigación pregunta: ¿cómo percibieron la docencia los docentes recién graduados, desde la pasantía supervisada en la escuela primaria por la que experimentaron? Los resultados mostraron que la pasantía es una experiencia notable en la formación inicial de profesores; aunque relevante, no proporciona todas las bases para actuar profesionalmente, pero hace aportes fundamentales para los futuros docentes.

PALABRAS CLAVE: Prácticas supervisadas. Formación de profesores. Narrativas.

\section{INTRODUÇÃO}

Nesta pesquisa, focalizamos as percepções de pedagogas/os egressas/os ${ }^{1}$ de uma instituição de ensino superior privada do curso de Pedagogia, da cidade de Caxias (interior do Maranhão) no sentido de perceber a docência a partir da realização do Estágio Supervisionado nos anos iniciais do Ensino Fundamental, detendo-se, entre outras questões, a como seria ministrar as aulas, a didática, o planejamento, a avaliação e outras tantas dimensões do ser, fazer e saber da docência; aos desafios, dificuldades e dilemas enfrentados no cotidiano profissional; a experiência de ter o primeiro contato com uma sala de aula, e outros aspectos que consubstanciam-se no pensar, fazer e refletir das/os professoras/es em ação.

Este estudo específico busca desvelar algumas compreensões e reflexões mediadas por nós, que se correlacionou com uma pesquisa maior que desenvolvemos no Mestrado em Educação na Universidade Federal do Rio Grande do Norte-UFRN, que tematizou: "A prática pedagógica no cotidiano de professoras iniciantes: tramas e desafios do aprender a ensinar" (MORAIS, 2015), financiada pela Coordenação de Aperfeiçoamento de Pessoal de Nível Superior-CAPES.

$\mathrm{Na}$ tentativa de tentar compreender como as/os professoras/es enfrentaram a docência, realizamos uma pesquisa qualitativa, por meio do desenvolvimento dos dispositivos metodológicos: conversas e questionário. Este último, constituído de perguntas abertas, direcionadas a um grupo de dez sujeitos, no intuito de buscar as

\footnotetext{
1 “Considerando a significativa presença feminina no magistério, em geral, e dos anos iniciais do ensino fundamental, em especial, bem como a centralidade das questões de gênero na problematização histórica, política e epistemológica da formação, optamos por usar "professoras/es" quando nos referirmos a abordagens gerais sobre o campo e apenas pelo feminino quando tratarmos da especificidade da presente pesquisa". (BRAGANÇA, 2018, p.3)
} 
revelações expressas, por meio da subjetividade dos interlocutores da pesquisa, dando primazia ao que conceberam narrativamente na experiência que tiveram no Estágio Supervisionado no Ensino Fundamental, enquanto professoras/es.

Durante a pesquisa realizada, na qual priorizamos dez interlocutoras/es recémformadas/os em Pedagogia, sendo apenas um do sexo masculino e as demais do sexo feminino, encontramos inúmeros resultados que serão expressos a seguir, apresentados em agrupamentos de narrativas dos participantes do estudo.

A pesquisa priorizou como dispositivos metodológicos: conversas e questionário de caráter narrativo, constituído de 05 (cinco) questões abertas, afim de favorecer a produção de narrativas dos sujeitos participantes do estudo, dando primazia à partilha de suas subjetividades e singularidades que pudessem revelar cada uma/um.

Apresentamos como problema de pesquisa: como as/os professoras/es recémformadas/os percebem o início da docência a partir da realização do Estágio Supervisionado no Ensino Fundamental pelo qual vivenciaram?

Partindo dessa questão, elaboramos como objetivo geral: compreender como as/os professoras/es recém-formadas/os perceberam a docência a partir da experiência do Estágio Supervisionado no Ensino Fundamental; e como objetivos específicos, buscamos: identificar as dificuldades, dilemas e desafios enfrentados no Estágio Supervisionado nos anos iniciais do Ensino Fundamental, bem como refletir acerca das diretrizes e modelos pelos quais estão erigidos os cursos de formação de professores para atuar no Ensino Fundamental.

O trabalho docente é constituído de uma variedade de atribuições e modos de ser e fazer no cotidiano escolar, e as/os professoras/es experientes já conhecem as facetas deste universo; enquanto que, aquelas/es que ainda não experienciaram a prática do ensino, e se encontram em processo formativo, precisam, se aproximar desses desdobramentos para conduzir qualitativamente as dinâmicas da sala de aula, contribuindo na tessitura da profissionalização docente.

Com isso, percebemos a necessidade de compreender o que as/os professoras/es recém-formadas/os pensam sobre o ensinar, a partir de experiências vivenciadas pelo Estágio Supervisionado nos anos iniciais do Ensino Fundamental, para que, então, possamos tecer reflexões e compartilhar experiências e conhecimentos com os formadores de professores, e aos futuros professoras/es, entre outros sujeitos, comprometidos e envolvidos com a educação.

\section{O desvelar da docência na experiência de pedagogas/os por meio do Estágio Supervisionado: tecendo reflexões}

O corpo de conhecimentos trabalhados na licenciatura em Pedagogia, tem como pressuposto o esclarecimento, aprofundamento e direcionamento, dentre outros elementos, para os sujeitos que estão cursando, no sentido de prepará-los para atuar nas instituições educacionais, em atividades que estejam relacionadas com os conhecimentos didáticos e pedagógicos no âmbito do trabalho educativo.

O currículo do curso de Pedagogia, portanto, deve expressar uma aproximação o mais estreita possível dos acontecimentos que são processados na realidade das escolas e dos sujeitos que nela atuam, para que a formação não seja apenas constituída por um viés eminentemente teórico, abstrato ou operacional, sem considerar os contextos educacionais variados, multidimensionais e plurais, pelos quais perpassam a educação 
escolar a partir da realidade concreta com que enfrentam as/os professoras/es e demais agentes educativos.

Quanto ao Estágio Supervisionado, este deve ser experienciado como um processo transitório de contribuições entre escola-academia, e vice-versa, e:

[...] Por isso, não basta ir à escola-campo. É necessário, em concomitância e/ou a posteriori, que as observações e/ou participações realizadas pelos alunos sejam consideradas no currículo do curso de formação; dentro de um espaço/tempo, privilegiado para uma análise crítica e diálogo, na tentativa de integrar a realidade profissional com os aspectos estudados no curso (GIROTTO; CASTRO, 2013, p. 178).

Com essa dinamicidade vivenciada na formação inicial, é possível fazer com que as/os futuras/os professoras/es possam buscar, das situações conflitantes, a transformação em situações concretas, possibilitando, assim, desenvolvimentos significativos e sem incorrerem em subterfúgios no processo de ensino e aprendizagem.

As disciplinas, por exemplo, que antecedem os estágios nas licenciaturas expressos na matriz curricular dos cursos, têm a intenção de diminuir os impactos e mesmo dar direcionamentos as/aos futuras/os professoras/es para saberem conduzir as atividades, configurando-se como uma simulação, que tem como foco principal à docência, sobretudo, na Educação Infantil e anos iniciais do Ensino Fundamental do $1^{\circ}$ ao $5^{\circ}$ ano, como preconiza a Lei de Diretrizes e Bases da Educação Nacional $n^{\circ}$ 9.394/96 (BRASIL, 1996). Por isso, “o estágio é um componente do currículo que não se configura como uma disciplina, mas como uma atividade" (PIMENTA, 2011, p. 121 ), tendo em vista que além de possuir uma carga horária maior, coloca os sujeitos frente às experiências docentes, ao encontro com as práticas desenvolvidas nos segmentos com os quais as/os pedagogas/os desenvolvem suas aprendizagens ao mesmo tempo aprendendo a ensinar, praticando seus saberes e saberes-fazeres, passando a ampliar sua visão com o que é oportunizado pelo contato com os alunos, professoras/os, equipe de gestão escolar e os funcionários técnico-administrativos que compõem os espaços do cotidiano escolar.

Partindo dessa definição "entende-se o estágio como uma oportunidade de inserção numa realidade, no caso escolas de educação básica, permitindo a confrontação do saber acadêmico com o saber da escola, permitindo aos estudantes apreender como se dão as relações de trabalho" (GISI; MARTINS; ROMANOWSKI, 2009, p. 208). Por esse viés, desenvolve-se a compreensão das relações educacionais na escola, e na academia, das/os futuras/os professoras/es, passando a articular-se com projeções que as/os mesmas/os desejam efetivar quando estiverem atuando profissionalmente.

\section{Perspectiva metodológica e percursos da pesquisa}

Este estudo é de abordagem qualitativa por buscar desenvolver a produção do conhecimento científico a partir das interpelações entre pesquisadores e sujeitos participantes da pesquisa, tecendo, assim subjetividades que são relevadas por pessoas no contexto educacional, mais precisamente, por pedagogas/os as/os quais partilharam narrativas da aprendizagem e mobilização de saberes e fazeres permeados pela experiência do Estágio Supervisionado nos anos iniciais do Ensino Fundamental. 
A pesquisa foi realizada no primeiro semestre de 2019, onde demos primazia, enquanto dispositivos metodológicos: as conversas e questionário de caráter narrativo, constituído de 05 (cindo) perguntas abertas, tendo como participantes 10 (dez) Pedagogas/os recém-formadas/os, oriundas/os de uma instituição de Ensino Superior privada, localizada em Caxias, no interior do Maranhão. Quanto ao sexo das/os participantes do estudo, nove eram do sexo feminino e um do sexo masculino.

Para preservar a dimensão ética da pesquisa científica, não mencionaremos os nomes dos sujeitos participantes da pesquisa e sim utilizaremos identificações dos mesmos por meio de pseudônimos, com os quais selecionamos apenas algumas narrativas que consideramos mais contundentes e relacionadas com o interesse da presente pesquisa.

Assim, usamos pseudônimos de flores para nos reportar às narrativas dos/as pedagogos/as apresentadas nesse texto, em que as do sexo feminino foram: Rosa, Tulipa, Angélica, Margarida, Gardenia e Íris. Enquanto que do sexo masculino o nominamos por Jacinto. Mas só trazemos as narrativas de cinco desses participantes, os quais nos revelaram mais contundentes, de acordo com a proposta da presente pesquisa.

Quanto às conversas, estas foram realizadas durante o percurso da pesquisa, buscando falar da experiência de estágio com os sujeitos, e mesmo trazendo suas impressões, para depois mediar a elaboração por nós de um roteiro de perguntas que culminou no questionário narrativo, desenvolvido no final dos encontros que tivemos com cada um de forma individualmente para revelar, narrativamente, o que o estágio trouxe de aprendizagem, formação e construção do conhecimento do ser e fazer-se professor/a.

O contato com os sujeitos da pesquisa aconteceu através da rede social facebook, pois todos eram já conhecidos do pesquisador, primeiro autor deste artigo, por ter experenciado o estágio no mesmo período ${ }^{2}$, porém, em instituições diferentes. E então, a conversa veio como dispositivo metodológico especial, em que realizamos um conjunto de três encontros/conversas com cada uma/um, buscando explicitar as razões e motivos da pesquisa, convidando-as/os para participarem e pedindo a autorização para publicizarem suas narrativas, os quais foram todos de acordo com essa autorização, manifestando-a por escrito durante as conversas em relação ao aceite. E no último encontro, foi desenvolvido de forma mais pontual, o questionário que foi elaborado em função dos encontros que tivemos, buscando tematizar o que fora contemplado nas conversas.

Defendemos o uso da conversa como dispositivo metodológico na pesquisa científica, porque ela "[...] é uma possibilidade de alimentar a pergunta pelo sentido do educativo, do formativo. Não a abertura para um descritivismo ou interpretacionismo, mas uma abertura viva para dela sairmos diferentes de quando entramos" (RIBEIRO; SOUZA; SAMPAIO, 2018, p.172-173).

Com base nos dispositivos metodológicos, o questionário desenvolvido com as/os participantes da pesquisa, era constituído de cinco questões abertas, abordando o exercício da docência no Ensino Fundamental por meio da realização do Estágio Supervisionado. Primamos por este tipo de dispositivo, porque "[...] o sujeito pode

\footnotetext{
${ }^{2}$ Vale ressaltar que o Estágio Supervisionado nos anos iniciais do Ensino Fundamental, foi realizado pelas/os participantes da pesquisa no ano de 2011 quando estavam cursando Pedagogia em uma instituição da rede privada de ensino, e suas narrativas só foram reveladas no ano de 2019, no período de realizada desta pesquisa.
} 
elaborar as respostas, com suas próprias palavras, a partir de sua elaboração pessoal" (SEVERINO, 2007, p. 126), dando mais flexibilidade ao que quiserem revelar subjetivamente, contribuindo, assim, para a construção dos saberes e conhecimentos da pesquisa.

Através do questionário, que foram respondidos pelos sujeitos da pesquisa, emergiram as narrativas acerca da experiência do Estágio Supervisionado pelos quais vivenciaram. Assim, desenvolvemos o recurso das narrativas escritas de formação, como possibilidades de compreensão do universo simbólico de representações, entendimentos e reflexões produzidas pelos sujeitos da pesquisa em articulação com as compreensões que construímos, enquanto atividade mobilizada pelos pesquisadores.

Acerca das narrativas escritas, nos amparamos na abordagem da pesquisa narrativa (auto)biográfica, com a qual traz uma relevância na produção do conhecimento científico, e que é essencial no campo da educação. Ou seja, compreendemos que:

[...] a narrativa escrita apresenta um corpo fenomenológico, cuja função é evidenciar como um indivíduo toma forma singular no decorrer do seu incessante trabalho de ajustamento entre as injunções socioculturais dos territórios a que pertence e as emergências da sua intencionalidade (JOSSO, 2010, p.212).

Assim, é por meio das narrativas que temos acesso à subjetividade que vai compondo o tecido da vida, experiência e formação dos sujeitos em diferentes espaçostempos por onde se entrelaçam e que constitui a sua história de vida, inscrevendo-se no contexto da sociedade e do tempo em que está imerso.

Como critério de exclusão dos sujeitos, priorizamos apenas àqueles que ainda não tinham vivenciado a experiência como docentes no Estágio Supervisionado, enquanto os que já a vivenciaram não fizeram parte deste estudo. Justamente, por buscar saber como percebiam o estágio a partir da primeira experiência de ir constituindo suas identidades do ser professor/a, mesmo ainda não tendo atuado como docentes no contexto de um desenvolvimento profissional de professor/a.

As questões narrativas produzidas com os sujeitos participantes da pesquisa giravam em torno das experiências tidas como professoras/es iniciantes, por intermédio do Estágio Supervisionado no Ensino Fundamental de $1^{\circ}$ ao $5^{\circ}$ ano, buscando esclarecimentos acerca das percepções das/os respondentes, em torno de como tinham sido estas experiências, bem como, as expectativas, dilemas e desafios que as/os mesmas/os enfrentaram no cotidiano do estágio realizado nas escolas de Ensino Fundamental, no período que estavam realizando o curso de Pedagogia, e que foram reveladas após a conclusão desse curso. Portanto, os sujeitos usaram o recurso da memória para ter acesso ao que tiveram de experiências no passado no estágio.

Apresentamos as respostas dos sujeitos participantes da pesquisa, agrupados por meio de eixos temáticos, que são intitulados, de acordo com o que nos foi relevado. Assim, designamos as/os interlocutoras/es por pseudônimos, de forma assimétrica, priorizando fundamentalmente as ideias pelas quais se aproximam umas das outras, de acordo com os eixos temáticos por nós elaborados, retirados dos contextos narrativos da pesquisa com os sujeitos. 


\section{As narrativas de pedagogas/os acerca do estágio supervisionado}

\section{Eixo 1 - Estabelecendo uma relação entre Teoria/Prática}

Ao serem questionados sobre atuar como professor por intermédio do estágio supervisionado no Ensino Fundamental, os participantes disseram em suas narrativas:

\footnotetext{
- Muito bom, pois a partir desta etapa você passa a ter a noção da prática, ou melhor, você vive a prática se colocando em prática (Narrativa de Jacinto, 2019).

- Foi uma experiência incrível e inexplicável, me deu uma base, mas não o alicerce da docência (Narrativa de Íris, 2019).

- Pra mim foi gratificante, porque me proporcionou o contato direto com a realidade e fazer a relação da teoria com a prática, e é justamente nesse contato que temos aquele 'choque' o que na maioria das vezes pode nos estimular ou não (Narrativa de Rosa, 2019).
}

Dessa forma a prática docente revela-se substancialmente como o momento em que oportuniza o desenvolvimento das aprendizagens construídas na formação inicial. Percebemos, ainda, com base nas narrativas das/dos pedagogas/os, que existe uma necessidade de uma melhor preparação para atuar na docência, o que somente a formação inicial não dá conta.

O último posicionamento acima, de Rosa, representa um discurso bastante presente no cenário educacional, ao mesmo tempo em que mostra a percepção de compreensão de como se constitui o cotidiano da educação escolar, e, que, de certo modo, permite a consolidação de esclarecimentos sobre a realidade que a escola vive, o que se faz necessário para as/os futuras/os professoras/es.

Por outro lado, buscando situar a relevância da construção de uma profissão docente sólida e política, tanto para as/os professoras/es que estão no exercício da docência, quanto para as/os futuras/os docente, Nóvoa (2009, p. 19) nos diz que "não é possível preencher o fosso entre os discursos e as práticas se não houver um campo profissional autónomo, suficientemente rico e aberto", o que requer a concentração, por parte das/os professores e professoras de esforços que vão muito mais além, do que apenas esperar iniciativas do sistema educacional, mas deve-se focalizar a participação em outros grupos sociais, debates, reuniões e organizações que lutam pela valorização dos profissionais da educação, buscando então ressituar o prestígio social que a profissão enseja.

Eixo 2 - Principais impactos da prática docente visibilizados pelas/os Pedagogas/os no estágio

Numa perspectiva a posteriori da realização do estágio no Ensino Fundamental, as narrativas concernentes a essa experiência revelaram que as/os pedagogas/os conseguem associar uma correlação universidade/escola, por meio de diferenças e ambiguidades percebidas entre essas instituições. 
Assim, as narrativas das/os pedagogas/os, quando rememoraram o estágio que experienciaram no Ensino Fundamental, mostraram alguns impactos que tiveram entre a transição da universidade à escola, aspectos esses que tem sido uma constância em muitos estagiários que enfrentam esse contexto e também revelado em outros tantos estudos da área (PIMENTA, 2011; MORAIS, 2015). Conforme pontuavam acerca disso em suas narrativas, revelam o seguinte:

\footnotetext{
- Que os professores precisam renovar suas aulas, interagir com os alunos para que os mesmos possam dar mais valor à disciplina e assim contribuindo com uma aula prazerosa (Narrativa de Margarida, 2019).

- Pouca prática explorada, e muita teoria lida e praticada não vivenciada no dia a dia no contexto escolar (Narrativa de Íris, 2019).
}

Diante do exposto, depreendemos que a prática pedagógica pode encontrar-se permeada por uma rotina e um saber-fazer quase que em um modus operandi, talvez pelo tempo de experiência com o qual se encontra a/o professor ou professora regente da sala de aula, e por outras tantas questões quer perpassam o desenvolvimento profissional docente, sobretudo, os aspectos relacionados com a: valorização profissional docente, condições de trabalho, formação continuada, políticas educacionais, relação professor-aluno, ausência dos pais na escola, enfim, uma série de questões que ao longo do tempo vão desgastando a docência, bem como o seu saber e fazer, que ultrapassam as lógicas apresentadas pelo olhar de um observador que apenas passa pouco tempo na escola, como no caso dos estagiários quando estavam na condição desse status. São questões que precisam ser consideradas e refletidas no campo da educação, pois, na escola pública, muitos são os desafios a enfrentar.

Por outro lado, cabe enfatizar que o cotidiano da sala de aula é multifacetado e imprevisível mostrando contextos adversos e inesperados, requerendo uma atuação dinâmica por parte das/os docentes. Porém, nem sempre o que se vê em um curto espaço de tempo, se desdobra na realidade, pois "a prática apresenta características ambíguas, oscilantes e fragmentadas, dificultando a obtenção de uma visão global do trabalho docente" (GUARNIERI, 2005, p. 19). Assim, para bem ensinar o professor ou professora tem que conhecer e saber o quê, para quê, e por que ensinar determinados conhecimentos e não outros, pois "[...] somente faz o aluno aprender o professor que bem aprende" (DEMO, 2004, p. 120), o que remete ao fato de que as/os docentes tem que mobilizar competentemente seus saberes e fazeres no ensino, para permitir que seus alunos construam aprendizagens significativas.

A formação docente é convidada a articular-se com as prerrogativas instituídas no cenário social, econômico e cultural mais amplo, não se prendendo às discussões acadêmico-científicas, mas expandir-se para contextos variados para que as/os futuras/os professoras/es tenham referências para proceder nas situações, por vezes, apresentadas em sua trajetória de formação pessoal e profissional, e poder encarar as instabilidades que são experienciadas na sala de aula, e na escola como um todo, encontrando possibilidades.

E para que sejam atenuados os impactos que são enfrentados pelas/os professoras/es ou futuras/os professoras/es, é importante o conhecimento da realidade escolar, evitando os surtos e "choques de realidades" como retratadas nas narrativas acima. Para isso: 
Os futuros professores e professoras também devem estar preparados para entender as transformações que vão surgindo nos diferentes campos e para ser receptivos e abertos a concepções pluralistas, capazes de adequar suas atuações às necessidades dos alunos e alunas em cada época e contexto. Para isso é necessário aplicar uma nova metodologia e, ao mesmo tempo, realizar uma pesquisa constante (o professor é capaz de gerar conhecimento pedagógico em sua prática) que faça mais do que lhes proporcionar um amontoado de conhecimentos formais e formas culturais preestabelecidas, estáticas e fixas, incutindo-lhes uma atitude de investigação que considere tanto a perspectiva teórica como prática, a observação, o debate, a reflexão, o contraste de pontos de vista, a análise da realidade social, a aprendizagem alternativa por estudos de casos, simulações e dramatizações (IMBERNÓN, 2010, p. 64).

É por meio do contato de professores e professoras com os níveis de exploração de suas experiências, aprendizagens e conhecimentos que se poderá compreender com mais facilidades todas e quaisquer dificuldades que surgirem no ensino, bem como criar possibilidades outras para desenvolvê-las.

De certo modo, o que é experienciado no primeiro contato com as escolas são apenas uma visão parcial do processo, mas que vai alargando as possibilidades de entendimento de como funcionam os vários setores e o trabalho dos agentes que habitam o espaço escolar, bem como dos aspectos comportamentais, emocionais, biológicos, sociais e etc., dos/as alunos/as, principalmente, e de todos os outros sujeitos presentes nesta instituição. Essa abertura maior é propiciada pelos vários momentos com que os especialistas (formadores de professoras/es), os/as supervisores/as de estágio e as/os professoras/es da escola, proporcionam aos sujeitos em formação no contato com as escolas, ao longo do curso de formação inicial na graduação, e que deve ser conduzido desde o início do curso de licenciatura.

Diante dessa perspectiva, o que geralmente acontece, quando as/os futuras/os professoras/es adentram a instituição escolar, é tentar modificar os elementos do fazer que possam ganhar outra feitura, diferente do que fora observado nos períodos experienciados por intermédio dos estágios supervisionados. Por isso, a formação inicial de professoras/es é crucial para a construção e desenvolvimento das dimensões didáticas, teóricas e metodológicas das mais variadas perspectivas e dimensões, que são necessárias ao desenvolvimento que a escola, e consequentemente, as/os alunas/os necessitam. Dessa forma:

Esta formação se constitui pelo entrelaçamento de processos cognitivos, afetivos, sociais, morais, dos conhecimentos, dos fazeres, das tomadas de decisão, da solução de impasses, da lida com as ambiguidades e as diferenças, do uso das técnicas ou de recursos diversos, etc., na direção de um pensar que possa distinguir fatos e questões, ter sentido crítico na direção de uma autonomia para escolhas (GATTI, 2009, p. 92).

O processo de formação docente, portanto, é permeado por um cenário multifacetado em que se consolida os saberes e fazeres da profissão, e o estágio traz uma potencialidade formativa especial que contribui para a escolha da área que o sujeito quer atuar. 
Essa formação docente, trata, pois, de uma adequação ao que se apresenta emergente na educação escolar, como forma de superação de um modelo fechado e intransponível, e que, obviamente seja exequível, a tal ponto que atenda às necessidades evidenciadas nos contextos de atuação das/os futuras/os professoras/es.

\section{Eixo 3 - Dificuldade, dilemas e desafios da docência}

Quando as/os futuras/os professoras/es revelam suas dificuldades, dilemas e desafios acerca do processo de ensinar, estes aspectos, que são relevantes, precisam ser compreendidos à luz do que a prática evidencia, juntamente com um entrelaçamento das teorias subjacentes ao campo educacional no que diz respeito ao currículo escolar, as etapas de desenvolvimento das aprendizagens dos educandos, às políticas educacionais e outras, articulada com o que perpassa essas dimensões, como a realidade das escolas, as condições socioeconômicas, históricas e culturais de alunas/os e professoras/es, e as próprias condições nas quais o sistema educacional se erige, para entendê-las e então estabelecer pontos de ligação entre o que, de fato, está sob a responsabilidade do sistema educacional, e sob a responsabilidade dos próprios sujeitos enquanto inseridos em um dado contexto e tempo histórico-social de transformações contínuas.

Dessa forma, as narrativas, segundo o eixo tematizado nesta seção, permeandose pela didática desenvolvida pelos sujeitos participantes da pesquisa, quando estavam atuando no Estágio Supervisionado nos anos iniciais, mostraram-se com as seguintes caracterizações:

- [...] a minha maior dificuldade foi a de preparar um plano de aula de acordo
com a realidade encontrada em sala (Narrativa de Rosa, 2019).

- As dificuldades foram: em preparar as aulas (Narrativa de Margarida, 2019).

- [...] saber direcionar os assuntos para os alunos na questão da aplicação de atividades (Narrativa de Tulipa, 2019).

Percebemos no grupo dessas três falas, uma convergência de ideias, advindas dos conflitos em como preparar as aulas, assim como uma preocupação de quais conteúdos, metodologias e formas de atuação podem amparar a/o futura/o professora e o professor, razão pela qual ainda se sentem inseguras/os ao ministrarem suas aulas e/ou atividades por meio dos estágios supervisionados.

Outras informações recaíram sobre o sistema educacional, apontando que: “[...] a educação perde muito por causa da estrutura física do espaço escolar, o número alto de alunos por sala de aula também impede o bom desenvolvimento do trabalho do profissional (Narrativa de Jacinto, 2019)".

Essa assertiva também foi encontrada nas narrativas de Íris, Gardenia e Angélica. Assim, essa, talvez, pareça ser uma das maiores dificuldades de realização de um trabalho de qualidade pelas/os professoras/es, como bem aponta Jacinto. Portanto, as condições estruturais dos espaços das escolas, tem como fator determinante a inexistência de políticas públicas eficazes, que é a dimensão imaterial do processo, isto é, alunas/os oriundas/os de fragmentação familiar com alta vulnerabilidade social, e as brechas no que diz respeito à falta de comprometimento, responsabilidade $\mathrm{e}$ 
envolvimento de algumas/alguns professoras/es com o processo de ensino e aprendizagem e seu papel político-social e educacional podem deflagrar o campo educacional e dificultam qualitativamente o trabalho pedagógico das/os docentes. Assim:

\begin{abstract}
Não se pode culpar a educação por algo que ela não originou, mas que é fruto da atual reorganização dos mercados, da produção capitalista e do reaparecimento das ideologias e dos discursos legitimadores e promotores de concepções de sociedade coerentes com essa perspectiva monetarista e consumista da vida (TORRES SANTOMÉ, 2003, p. 37).
\end{abstract}

A intenção do Estado é forjar uma cultura utilitarista, coisificando os sujeitos a partir dos segmentos escolares, preparando-os para inseri-los no mercado produtivo e que possa reproduzir os ditames da supremacia mercadológica estatal na sociedade. Por isso, não se interessam muito por uma política rigorosa de investimento educacional, que é tolhida pelos organismos internacionais de investimento na educação como o Fundo Monetário Internacional (FMI) e o Banco Mundial, entre outros.

Percebemos que os contatos estabelecidos das/os futuras/os professoras e professores com as escolas em decorrência do estágio, é um processo de análise e reflexão da realidade, que passa a ser revelado nas discussões e socializações com seus pares e suas/seus docentes na academia, quando no transcurso da graduação, e para outros sujeitos com os quais estabelecem relações em vários contextos, não somente os escolares. Contudo, "a reflexão sobre a prática, sua análise e interpretação constroem a teoria que retorna à prática para esclarecê-la e aperfeiçoá-la" (PIMENTA, 2011, p. 71), e é nesse trajeto, de pensamento e ação que fornece pistas de construção de práticas e reflexões novas, ou mesmo, de adaptabilidade às condições que, por vezes, podem não se apresentar à altura do desejado, com esse entrelaçamento chega-se a um determinado fator comum.

Ser professor e desenvolver uma didática no contexto da prática pedagógica, é uma atividade dinâmica, que oscila entre o que é, e o que deve ser, partindo a ser suscitado pelos sujeitos no enfrentamento das situações que experienciam cotidianamente nestes contextos. Com isso permite a construção de conhecimentos. Portanto, ressaltamos que "o conhecimento está situado na ação, nas decisões e nos juízos feitos pelos professores. Esse conhecimento é adquirido por meio da experiência e da deliberação, e os professores aprendem quando têm oportunidade de refletir sobre o que fazem" (MARCELO GARCIA, 2010, p. 15).

Enfim, inúmeros são os desafios colocados no campo da docência, sobretudo da formação de professoras/es para atuar na Educação Básica. Partindo desse pressuposto, concordamos que:

O desafio que temos pela frente é romper com uma excessiva uniformização escolar, que não consegue dar respostas úteis aos alunos e às distintas necessidades e projetos de vida de que eles são portadores. Hoje, talvez mais do que nunca, impõe-se reabilitar os modelos da "diversificação pedagógica" como referência para uma escola centrada na aprendizagem (NÓVOA, 2009, p. 65). 
Condições essas impostas tanto às/aos professoras/es que se encontram em um período prolongado na profissão, quanto aos que passam a estabelecer os primeiros contatos profissionalmente nos espaços de atuação, pois, a acelerada sociedade que vivemos, exige que sejamos mais atentos e conhecedores da realidade e de variados contextos, para que possamos decidir nas urgências e incertezas que surgem aonde quer que estejamos.

\section{CONSIDERAÇÕES FINAIS}

A formação docente, salvo significativas mudanças no cenário político (numa análise macroestrutural e panorâmica) e no campo de algumas práticas pedagógicas (numa análise microestrutural e específica), não se pode generalizar quanto ao fato de que todas as práticas são exitosas e sem presença de dificuldades. Existem sim inúmeros e peculiares fatores que condicionam o exercício de um trabalho de qualidade na educação escolar, para que almeje a tão sonhada qualidade que todos buscamos.

Como na formação de professoras/es, os estágios são atividades que contribuem para a construção de conhecimentos e práticas que alicerçarão a docência; a pesquisa nos mostrou que estes são importantes para que os sujeitos durante a sua formação possam estar se familiarizando continuamente, e então ir desvelando alguns ocultamentos não visibilizados no cotidiano como, por exemplo, as dificuldades de aprendizagem das/os alunas/os, a indisciplina de alguns, a dinâmica da avaliação e do planejamento educacional, a relação com os sujeitos que habitam a escola, a organização dos conteúdos de ensino, bem como a relação com as/os alunas/os, com os pais de alunos e com a comunidade, o que apenas pelas discussões e teorias não conseguem revelar, e ainda que, por mais que revelem situações que não estão previstas no currículo prescrito, a realidade vivenciada mostra-se com uma infinidade de gestos, posturas, aspectos emocionais, entonação da voz, comportamentos, etc., e que geralmente não são descritas nos estudos e leituras que são socializados na academia.

Nesse sentido, é notório salientar que para as/os professoras/es em formação, os estágios não cobrem toda e qualquer lacuna da formação, mas são componentes curriculares que dão um suporte para entender a realidade que as escolas apresentam para às/os futuras/os professoras/es, e que a prática profissional é o espaço, por natureza, de uma formação continuada, possibilitando em maior proporção, a constituição da profissão docente, nos contextos que serão aprofundados, razão pela qual, compreendendo-se esses fatores, torna-se mais fácil e menos ardoroso o trabalho pedagógico a ser desenvolvido na escola, sem, contudo, desconsiderar os conflitos que sempre surgirão, por um atributo da condição propiciadas das relações humanas, bem como de crises e instabilidades enfrentadas na própria profissão de professoras e professores, oportunizados pelo meio e que se revela em quaisquer que sejam as realidades exploradas pelas/os mesma/os.

Em suma, defendemos que o Estágio Supervisionado, é uma atividade privilegiada de contato com os sujeitos em formação para a escolha do campo profissional e com o qual possibilita a construção de múltiplas aprendizagens do ser e se fazer professora e professor e da cultura institucional de uma escola ou outra instituição educativa que estão imersos os sujeitos, bem como dos variados aspectos organizacionais, pessoais e institucionais pelos quais perpassam a vida, a formação e a profissão docente do sujeito. 
Ter essa experiência de estágio se torna indispensável para a construção da profissão docente, fazendo toda a diferença na formação e desenvolvimento profissional da/o futura/o professora/or.

\section{REFERÊNCIAS}

BRASIL. MEC. Lei de Diretrizes e Bases da Educação Nacional. Brasília: MEC, 1996. Disponível em: < http://portal.mec.gov.br/arquivos/pdf/ldb.pdf>. Acesso: 13 dez. 2019.

BRAGANÇA, Inês Ferreira de Souza. Formação inicial e continuada de professoras/es: contribuições da abordagem narrativa (auto)biográfica. São Paulo, Projeto de Pesquisa, FAPESP, 2018.

DEMO, Pedro. Professor do futuro e reconstrução do conhecimento. In.: MACIEL, E. S. B.; NETO, A. S. (Orgs.). Formação de professores: passado, presente e futuro. São Paulo: Cortez, 2004.

GATTI, Bernadete Angelina. Formação de professores: condições e problemas atuais. Revista Brasileira de Formação de Professores. v. 1, n. 1, p.90-102, maio/2009. Disponível em: < https://periodicos.itp.ifsp.edu.br/index.php/RIFP/article/view/347/360>. Acesso em: 28 out. 2019.

GIROTTO, Cyntia Graziela G. Simões; CASTRO, Rosane Michelli. O estágio curricular e a didática na formação de professores: desafios e possibilidades. Educação. Santa Maria, v. 38, n. 1, p. 177-190, jan./abr. 2013. Disponível em: > https://periodicos.ufsm.br/reveducacao/article/view/4094/4540>. Acesso: 03 set. 2020.

GISI, Maria Lourdes; MARTINS, Pura Lúcia Oliver; ROMANOWSKI, Joana Paulin. O estágio nos cursos de licenciatura. In.: ENS, R. T.; VOSGERAU, D. S. R.; BEHRENS, M. A. (Orgs.) Trabalho do professor e saberes docentes. Curitiba: Champagnat, 2009.

GUARNIERI, Maria Regina. O início da carreira docente: pistas para o estudo do trabalho do professor. In.: GUARNIERI, M. R. (Org.) Aprendendo a ensinar: o caminho nada suave da docência. 2.ed. Campinas, SP: Autores Associados; Araraquara, SP: Programa de Pós-graduação em Educação Escolar da Faculdade de Ciências e Letras da UNESP, 2005. (Coleção polêmicas de nosso tempo; 75).

IMBERNÓN, Francisco. Formação docente e profissional: formar-se para a mudança e a incerteza. Tradução Silvana Cobucci Leite. 8.ed. São Paulo: Cortez, 2010. 
JOSSO, Marie-Christine. Experiências de vida e formação. Tradução José Cláudio; Júlia Ferreira. Revisão científica Maria da Conceição Passeggi; Marie Christine Josso. 2.ed. rev.e ampl. Natal, RN: EDUFRN; São Paulo: Paulus, 2010.

MARCELO GARCIA, Carlos. O professor iniciante, a prática pedagógica e o sentido da experiência. In.: Formação Docente, Belo Horizonte, v. 03, n. 03, p. 11-49, ago./dez. 2010. Disponível em: <http://formacaodocente.autenticaeditora.com.br>. Acesso: 09 dez./2019.

MORAIS, Joelson de Sousa. A prática pedagógica no cotidiano de professoras iniciantes: tramas e desafios do aprender e ensinar. Dissertação (Mestrado em Educação), Centro de Educação, Universidade Federal do Rio Grande do Norte, Natal, 2015. 175f. Disponível em:

<https://repositorio.ufrn.br/jspui/bitstream/123456789/20460/1/JoelsonDeSousaMorais_ DISSERT.pdf>. Acesso em: 04 ago. 2019.

NÓVOA, António. Professores: imagens do futuro presente. Lisboa: Educa, 2009.

PIMENTA, Selma Garrido. O estágio na formação de professores: unidade teoria e prática? 10. ed. São Paulo: Cortez, 2011.

RIBEIRO, Tiago; SOUZA, Rafael de; SAMPAIO, Carmen Sanches. É possível a conversa como metodologia de pesquisa? In: RIBEIRO, T.; SOUZA, R. de; SAMPAIO, C. S. (Orgs,). Conversa como metodologia de pesquisa: porque não? Rio de Janeiro: Ayvu, 2018. P.163-180.

SEVERINO, Antônio Joaquim. Metodologia do trabalho científico. 23. ed. rev. e atual. São Paulo: Cortez, 2007.

TORRES SANTOMÉ, Jurjo. A educação em tempos de neoliberalismo. Trad. Cláudia Schilling. Porto Alegre: Artmed, 2003.

Recebido em:09/01/2020

Aprovado em: 05/03/2020 